\title{
Effects of inhaled nitric oxide for postoperative hypoxemia in acute type A aortic dissection: a retrospective observational study
}

Hang Zhang ${ }^{1,2 \dagger}$, Yaoyang Liu ${ }^{3 \dagger}$, Xiangdong Meng ${ }^{1 \dagger}$, Dicheng Yang ${ }^{1}$, Sheng Shi', Jian Liu', Zhongxiang Yuan ${ }^{1}$,

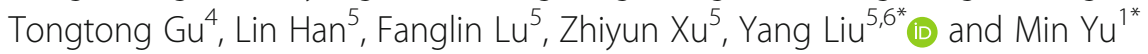

\begin{abstract}
Background: Postoperative hypoxemia in acute type A aortic dissection (AADA) is a common complication and is associated with negative outcomes. This study aimed to analyze the efficacy of low-dose (5-10 ppm) inhaled nitric oxide (iNO) in the management of hypoxemia after AADA surgery.

Methods: In this retrospective observational study, Medical records of patients who underwent AADA surgery at two institutions between January 2015 and January 2018 were collected. Patients with postoperative hypoxemia were classified as iNO and control groups. Clinical characteristics and outcomes were compared using a propensity score-matched (PSM) analysis.

Results: Among 436 patients who underwent surgical repair, 187 (42.9\%) had hypoxemia and 43 were treated with low-dose iNO. After PSM, patients were included in the iNO treatment $(n=40)$ and PSM control $(n=94)$ groups in a 1:3 ratio. iNO ameliorated hypoxemia at $6,24,48$, and $72 \mathrm{~h}$ after initiation, and shortened the durations of ventilator support (39.0 h (31.3-47.8) vs. $69.0 \mathrm{~h}(47.8-110.3), p<0.001)$ and ICU stay $(122.0 \mathrm{~h}(80.8-155.0)$ vs $179.5 \mathrm{~h}$ $(114.0-258.0), p<0.001)$. There were no significant between-group differences in mortality, complications, or length of hospital stay.

Conclusions: In this study, we found that low-dose iNO improved oxygenation in patients with hypoxemia after AADA surgery and shortened the durations of mechanical ventilation and ICU stay. No significant side effects or increase in postoperative mortality or morbidities were observed with iNO treatment. These findings warrant a randomized multicenter controlled trial to assess the exact efficiency of iNO for hypoxemia after AADA.
\end{abstract}

Keywords: Postoperative hypoxemia, Acute type A aortic dissection, Inhaled nitric oxide, Propensity analysis

\footnotetext{
* Correspondence: liuyang3722@163.com; minyudr@163.com

${ }^{+}$Hang Zhang, Yaoyang Liu and Xiangdong Meng contributed equally to this work.

${ }^{5}$ Department of Cardiovascular Surgery, Changhai Hospital, Second Military Medical University, Shanghai 200433, China

${ }^{1}$ Department of Cardiovascular Surgery, Shanghai General Hospital, Shanghai Jiao Tong University School of Medicine, No. 100 Haining Road, Shanghai 200080, China

Full list of author information is available at the end of the article
}

(C) The Author(s). 2020 Open Access This article is distributed under the terms of the Creative Commons Attribution 4.0 International License (http://creativecommons.org/licenses/by/4.0/), which permits unrestricted use, distribution, and reproduction in any medium, provided you give appropriate credit to the original author(s) and the source, provide a link to the Creative Commons license, and indicate if changes were made. The Creative Commons Public Domain Dedication waiver (http://creativecommons.org/publicdomain/zero/1.0/) applies to the data made available in this article, unless otherwise stated. 


\section{Introduction}

Acute type A aortic dissection (AADA) is a fatal condition. The mortality rate is $1-2 \%$ per hour on the first day, with nearly $50 \%$ of deaths occurring within the first week [1, 2]. Surgery is life-saving for most patients but may result in high postoperative morbidity $[1,2]$.

Postoperative hypoxemia is a serious complication with an incidence of 30-50\% [3, 4]. Hypoxemia occurs secondary to systemic and local inflammatory reactions after aortic vascular tissue destruction, ischemic/reperfusion injury, intraoperative cardiopulmonary bypass (CPB), deep hypothermia, and massive blood transfusion [4-7]. Hypoxic pulmonary vasoconstriction is inhibited, resulting in ventilation/perfusion mismatching and shunting [7]. Hypoxemia prolongs postoperative mechanical ventilation and intensive care unit (ICU) stay and increases postoperative mortality. However, effective medical interventions are limited and controversial [6-8].

Inhaled nitric oxide (iNO) is a selective pulmonary vasodilator that has long been used in the management of acute respiratory distress syndrome (ARDS), pulmonary hypertension, neonatal hypoxemic respiratory failure, and lung transplantations. To date, several randomized controlled trials and meta-analyses have concluded that iNO therapy wasn't beneficial to mortality or mechanical ventilation duration of patients with $\operatorname{ARDS}[9,10]$. However, postoperative hypoxemia in AADA was different with ARDS in etiology and pathophysiology. To the best our knowledge, no randomized controlled or casecontrol study has evaluated iNO treatment efficacy to this group of patients.

We previously found that iNO improved oxygenation after AADA and tended to decrease the time to extubation [11]. Herein, we retrospectively analyzed the effects of low-dose iNO therapy in patients with postoperative hypoxemia after AADA and evaluated its efficacy and safety.

\section{Patients and methods \\ Patients}

We retrospectively reviewed consecutive patients with AADA who underwent surgical repair from January 2015 to January 2018 at Shanghai General Hospital and Changhai Hospital.

The enrollment criteria were as follows: (I) patients who received repairment surgery for AADA; (II) patients with a persistent postoperative hypoxemia, which was defined as the blood gas exam showed that ratio of arterial partial pressure of oxygen $\left(\mathrm{PaO}_{2}\right)$ to fraction of inspired oxygen $\left(\mathrm{FiO}_{2}\right)$ was equal to or less than $200 \mathrm{mmHg}\left(\mathrm{PaO}_{2} / \mathrm{FiO}_{2} \leq 200\right)$ occurring within $24 \mathrm{~h}$ after ICU admission, lasting more than $2 \mathrm{~h}$, and in the absence of other causes of pulmonary insufficiency such as cardiogenic pulmonary edema, pneumonia, pleural effusion, segmental atelectasis, pneumothorax, and pulmonary artery embolism [12]. The exclusion criteria were as follows: (I) patients who died within $24 \mathrm{~h}$ after surgery; (II) patients who developed severe postoperative complications such as: coma, cardiogenic shock, and gastrointestinal ischemia. Eligible patients were divided into two groups: patients who received iNO (iNO group) and patients who were managed routinely (control group) (Fig. 1).

This study was approved by the Ethics Committee of Shanghai General Hospital, Shanghai Jiao Tong University School of Medicine, (No. 2018KY241) and the Committee on Ethics of Biomedicine Research, Second Military Medical University, Shanghai (No. SMMUEC2018-044), with the need for individual patient consent waived.

\section{Surgical procedures and standard postoperative ICU protocols}

All enrolled patients underwent aortic repair under extracorporeal circulation, deep hypothermic circulatory arrest, and selective cerebral perfusion. Repairment surgery for AADA was performed with the same standard surgical procedure. The surgical approaches are shown in Table 1 . The standard ICU protocols were approximately similar in both hospitals and included ventilator support, sedation, and pain management. Briefly, patients were placed on ventilators in synchronized intermittent mandatory ventilation (SIMV) or assist/control (A/C) modes set at $8-10 \mathrm{~mL} / \mathrm{kg}$ tidal volume and $5 \mathrm{cmH}_{2} \mathrm{O}$ positive end-expiratory pressure (PEEP). Arterial blood gases (ABG) were check every $30 \mathrm{~min}$ to $6 \mathrm{~h}$, depending on the patient's condition. Propofol at $20-50 \mu \mathrm{g} / \mathrm{kg} / \mathrm{min}$ was administered until the patient was awake. A continuous infusion of a small dose of fentanyl was administered until ventilator weaning. Routine management for postoperative hypoxemia included: (1) recruitment maneuvers with PEEP of $10-15 \mathrm{~cm} \mathrm{H}_{2} \mathrm{O}$; (2) negative fluid balance maintenance if hemodynamic stability could be achieved; (3) administration of methylprednisolone $40 \mathrm{mg}$ and ulinastatin 300,000 units intravenously twice daily for 3 days; (4) bilevel positive airway pressure (BiPAP) noninvasive ventilation support after extubation, when necessary.

Patients were extubated after meeting the following criteria: (1) alert and cooperative with adequate muscle strength; (2) hemodynamically stable with no signs of low cardiac output syndrome or myocardial ischemia, and minimal need for inotropic support (noradrenaline or adrenaline $\leq 0.05 \mu \mathrm{g} / \mathrm{kg} / \mathrm{min}$; (3) chest tube drainage < $50 \mathrm{~mL} / \mathrm{h}$ with no active bleeding; (4) acceptable ABG at $\mathrm{FiO}_{2} \leq 0.5$ and PEEP $\leq 5 \mathrm{cmH}_{2} \mathrm{O}$ of $\mathrm{PaO}_{2} \geq 80 \mathrm{mmHg}$, and $\mathrm{PaCO}_{2}<45 \mathrm{mmHg}$, in the absence of respiratory distress. Patients were transferred out of the ICU when hemodynamically stable, without serious complications, and with $\mathrm{PaO}_{2} \geq 80 \mathrm{mmHg}$ during $\mathrm{O}_{2}$ administration via Venturi mask or nasal cannula. 


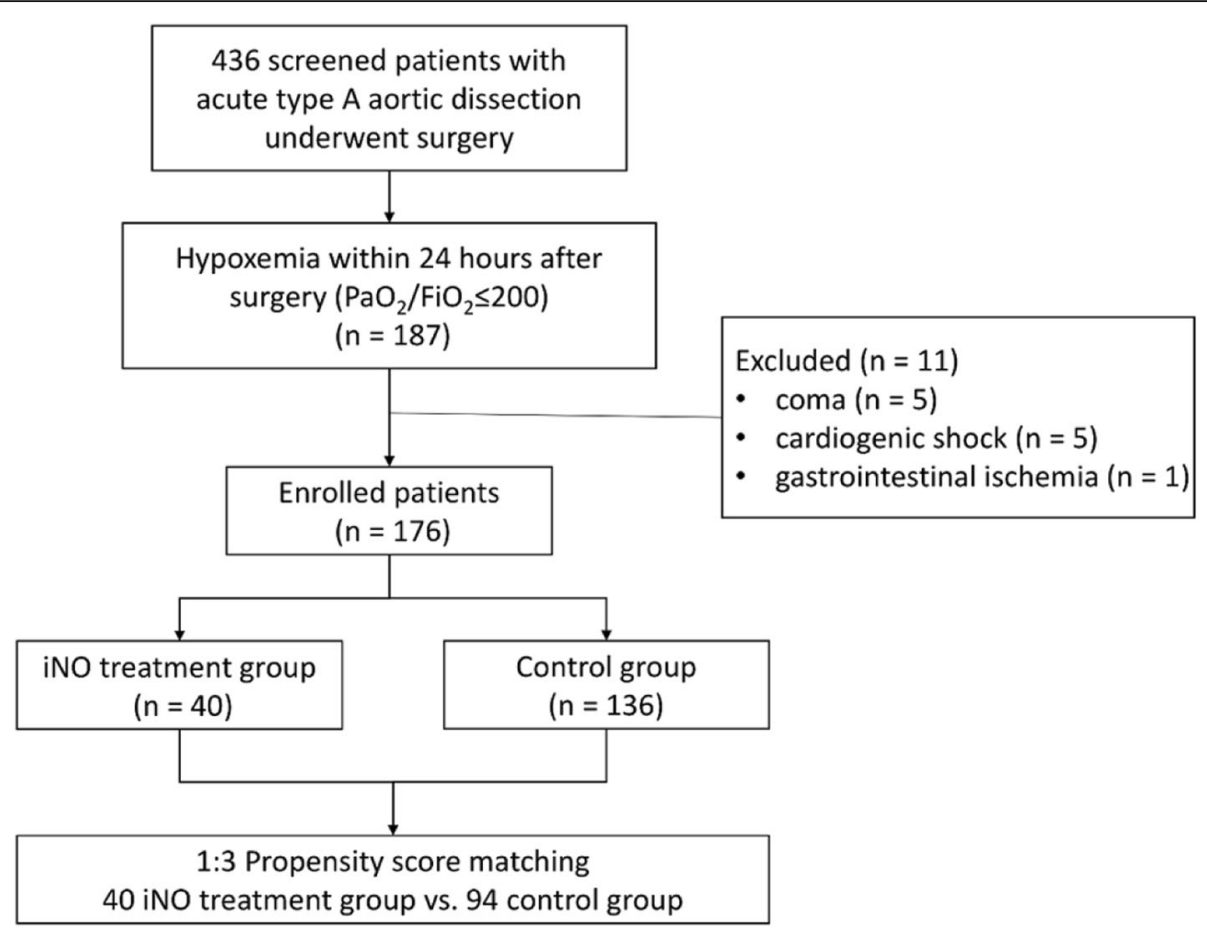

Fig. 1 Flowchart showing patients included in the analysis. iNO: inhaled nitric oxide

\section{iNO management}

At our institutes, iNO treatment is optional for symptomatic treatment of hypoxemia. Thus, iNO is administered at the discretion of the intensivist. A number of patients who met the criteria for hypoxemia received low dose iNO (5-10 ppm [ppm]) in addition to routine management. NO gases and equipment were supplied by the Children's Hospital of Fudan University, as previously described [13]. Briefly, the NO inhalation device was managed by a flow controller (MFC) (Shanghai Noventek, Shanghai, China). The $\mathrm{N}_{2}$-based gas mixture flowed into the breathing circuit. The $\mathrm{NO} / \mathrm{NO}_{2}$ electrochemical sensor (NOxBOX Plus; ${ }^{\oplus}$ Bedfont Scientific, Rochester, England) was placed in the breathing circuit near the intubation cannula. Continuous monitoring was instituted to maintain the iNO concentration at 5$10 \mathrm{ppm}$ and $\mathrm{NO}_{2}$ at less than $3 \mathrm{ppm}$. Methemoglobin (MetHb) levels were measured once daily using the Radical-7 pulse oximeter (Radical-7 ${ }^{\circ}$ Pulse COOximeter $^{\odot}$, Masimo, USA). Side effects included increasing pleural drainage, new-onset bleeding, and thrombocytopenia (platelet count $<500,000 / \mathrm{ul}$ ). If oxygenation did not improve within $24 \mathrm{~h}$, if any side effects were noted, or if abnormal methemoglobin and $\mathrm{NO}_{2}$ were observed, iNO therapy was discontinued. When the patient was extubated, iNO was administered via nasal cannula and weaned by decreasing the flow gradually within $24 \mathrm{~h}$.

\section{Outcomes}

The primary outcomes were: (1) $\mathrm{PaO}_{2} / \mathrm{FiO}_{2}$ collected at 7 time points: preoperative; postoperative ICU admission; first episode of hypoxemia; 4-6 h after iNO initiation (iNO group) or 4-6 h after hypoxemia onset (control group); 24, 48 , and $72 \mathrm{~h}$ postoperatively; and (2) duration of mechanical ventilation and length of ICU stay. Secondary outcomes included mortality, complications, and in-hospital stay. Possible iNO related side-effects such as pleural drainage and thrombocytopenia were also observed. Coma was defined by a complete absence of consciousness with computed tomography (CT)-proven cerebrovascular occlusion. Cardiogenic shock was diagnosed in the presence of sustained hypotension (systolic blood pressure $<90 \mathrm{mmHg}$ ) and low cardiac output, with a poor response to high-dose inotropes and vasopressors. Gastrointestinal ischemia was defined by clinical symptoms and CT angiography evidence of deficient gastrointestinal blood supply with mesenteric artery involvement. Renal insufficiency was defined by an estimated glomerular filtration rate (eGFR) $<60 \mathrm{ml} / \mathrm{min} / 1.73$ $\mathrm{m}^{2}$; acute kidney injury (AKI) was defined by either a $50 \%$ increase from baseline in serum creatinine within 7 days after surgery, or a $0.3 \mathrm{mg} / \mathrm{dl}$ increase in serum creatinine from baseline within 2 days after surgery. Hepatic insufficiency was defined by a serum transaminase concentration $>120 \mathrm{U} / \mathrm{L}$ (3 times the upper limit of normal), bilirubin concentration $>3 \mathrm{mg} / \mathrm{dL}$, or a diagnosis of cirrhosis. 
Table 1 Baseline characteristics of patients with AADA and hypoxemia within $24 \mathrm{~h}$ after surgery: pre-PSM

\begin{tabular}{|c|c|c|c|}
\hline Variable & Control $(N=136)$ & iNO treatment $(N=40)$ & $p$-value \\
\hline Age, y & $50.4 \pm 11.0$ & $49.9 \pm 11.2$ & 0.789 \\
\hline Men & $110(80.9)$ & $31(77.5)$ & 0.638 \\
\hline BMI & $26.5 \pm 2.7$ & $26.3 \pm 2.9$ & 0.707 \\
\hline \multicolumn{4}{|l|}{ Comorbidity } \\
\hline Hypertension & $96(70.6)$ & $32(80.0)$ & 0.240 \\
\hline Diabetes & $2(1.5)$ & $2(5.0)$ & 0.476 \\
\hline COPD & $3(2.2)$ & $1(2.5)$ & 1.000 \\
\hline Hepatic insufficiency & $4(2.9)$ & $1(2.5)$ & 1.000 \\
\hline Renal insufficiency & $27(19.9)$ & $12(30.0)$ & 0.174 \\
\hline Cerebrovascular event & $3(2.2)$ & $2(5.0)$ & 0.694 \\
\hline Myocardial infarction & $9(6.6)$ & $2(5.0)$ & 1.000 \\
\hline tamponade & $21(15.4)$ & $9(22.5)$ & 0.297 \\
\hline Marfan Syndrome & $6(4.4)$ & $3(7.5)$ & 0.711 \\
\hline Smoking & $32(23.5)$ & $8(20.0)$ & 0.640 \\
\hline \multicolumn{4}{|l|}{ Laboratory test } \\
\hline Leucocyte $\left(10^{9} / \mathrm{L}\right)$ & $12.0 \pm 4.0$ & $13.0 \pm 3.4$ & 0.147 \\
\hline Hemoglobin (g/L) & $132.0(123.0,143.0)$ & $137.5(124.8,150.3)$ & 0.112 \\
\hline Platelet $\left(10^{9} / \mathrm{L}\right)$ & $147.0(121.3,201.8)$ & $161.5(140.5,200.0)$ & 0.317 \\
\hline $\mathrm{ALT}(\mathrm{U} / \mathrm{L})$ & $26.5(19.3,38.0)$ & $30.5(19.0,41.4)$ & 0.930 \\
\hline Creatinine $(\mu \mathrm{mol} / \mathrm{L})$ & $85.0(68.0,107.8)$ & $89.5(70.3,132.0)$ & 0.437 \\
\hline Troponin I (ng/ml) & $0.02(0.01,0.05)$ & $0.02(0.01,0.09)$ & 0.782 \\
\hline $\mathrm{PaO}_{2}(\mathrm{mmHg})$ & $85.5(71.2,101.7)$ & $80.0(67.7,109.2)$ & 0.897 \\
\hline \multicolumn{4}{|l|}{ Surgical procedure } \\
\hline Total arch replacement & $129(94.9)$ & $38(95.0)$ & 1.000 \\
\hline Hemi arch replacement & $7(5.1)$ & $2(5.0)$ & 1.000 \\
\hline Concomitant CABG & $10(7.4)$ & $2(5.0)$ & 1.000 \\
\hline \multicolumn{4}{|l|}{ CPB } \\
\hline CPB time (min) & $167.5(143.5,186.8)$ & $162.5(147.0,191.5)$ & 0.806 \\
\hline ACC time (min) & $97.5(84.0,109.8)$ & $96.0(87.3,117.3)$ & 0.604 \\
\hline DHCA time (min) & $28.0(22.0,31.8)$ & $24.0(19.0,28.0)$ & $0.041^{*}$ \\
\hline Minimum temperature in $\mathrm{CPB}\left({ }^{\circ} \mathrm{C}\right)$ & $22.3(22.1,24.4)$ & $22.1(21.5,23.5)$ & $0.040^{*}$ \\
\hline $\mathrm{PaO}_{2} / \mathrm{FiO}_{2}$ ratio meet hypoxemia criteria & $112.9(94.3,155.0)$ & $95.0(82.9,127.1)$ & 0.076 \\
\hline
\end{tabular}

AADA Acute type A aortic dissection, PSM Propensity score-matching, iNO Inhaled nitric oxide, BMI Body mass index, COPD Chronic obstructive pulmonary disease, ALT Alanine transaminase, CABG Coronary artery bypass graft, CPB Cardiopulmonary bypass, ACC Aortic cross-clamp, DHCA Deep hypothermic circulatory arrest, $\mathrm{PaO}_{2}$ Partial pressure of oxygen, $\mathrm{FiO}_{2}$ Fraction of inspired oxygen ${ }^{*} p<0.05$

\section{Statistical methods}

The data analysis was performed using SPSS 24.0 statistical software (IBM Corp., Armonk, NY, USA). Continuous variables with normal distribution were presented as means \pm standard deviations. Variables with skewed distribution data were presented as medians and interquartile ranges. Categorical variables were expressed as numbers and percentages. Continuous variables were compared using the t-test or Mann-Whitney U-test and categorical variables were compared using the chi- square test or Fisher's exact probability method. The $\mathrm{PaO}_{2} / \mathrm{FiO}_{2}$ ratio at different time points was compared using the variance of repeated measurement data and the least significant difference (LSD) method was used for pairwise comparisons. $p<0.05$ was considered statistically significant.

The propensity score matching (PSM) analysis was conducted using the R plug-in (PSM extension) in SPSS 24.0 (IBM Corp.), with a nearest-neighbor matching algorithm (1:3) and a caliper of 0.2. Propensity scores 
were generated using a multivariable logistic regression analysis model based on the following covariates: age, deep hypothermic circulatory arrest time, minimum temperature in $\mathrm{CPB}$, and $\mathrm{a} \mathrm{PaO}_{2} / \mathrm{FiO}_{2}$ ratio that met hypoxemia criteria.

\section{Results}

Among 436 patients who underwent AADA surgery, 187 (42.9\%) had hypoxemia and 43 were treated with lowdose iNO. After excluding coma $(n=5)$, cardiogenic shock $(n=5)$, and gastrointestinal ischemia $(n=1), 176$ patients were included 40 and 136 in the iNO and control groups, respectively. Profound hypothermic circulatory arrest time and minimum CPB temperature were significantly different between the groups (Table 1). PSM was used to balance the baseline covariates. After PSM, patients were included in the iNO and control groups in a 1:3 ratio (Fig. 1). All reported parameters were balanced in both groups and no significant differences were detected (Table 2).

After PSM, the durations of mechanical ventilation and ICU stay were significantly shorter in the iNO group

Table 2 Baseline characteristics of patients with AADA and hypoxemia at $24 \mathrm{~h}$ after surgery: post-PSM

\begin{tabular}{|c|c|c|c|}
\hline Patients' Characteristics & Control $(N=94)$ & iNO treatment $(N=40)$ & $p$-value \\
\hline$\overline{A g e}, y$ & $50.5 \pm 11.2$ & $49.9 \pm 11.2$ & 0.763 \\
\hline Men & $75(79.8)$ & $31(77.5)$ & 0.766 \\
\hline BMI & $26.1(24.9,28.6)$ & $26.5(24.5,27.7)$ & 0.719 \\
\hline \multicolumn{4}{|l|}{ Comorbidity } \\
\hline Hypertension & $65(69.1)$ & $32(80.0)$ & 0.199 \\
\hline Diabetes & $1(1.1)$ & $2(5.0)$ & 0.159 \\
\hline COPD & $2(2.1)$ & $1(2.5)$ & 0.894 \\
\hline Hepatic insufficiency & $1(1.1)$ & $1(2.5)$ & 0.530 \\
\hline Renal insufficiency & $20(21.3)$ & $12(30.0)$ & 0.163 \\
\hline Cerebrovascular event & $2(2.1)$ & $2(5.0)$ & 0.734 \\
\hline Tamponade & $17(18.1)$ & $9(22.5)$ & 0.554 \\
\hline Myocardial infarction & $8(8.5)$ & $2(5.0)$ & 0.479 \\
\hline Marfan Syndrome & $3(3.2)$ & $3(7.5)$ & 0.270 \\
\hline Smoking & $23(24.5)$ & $8(20)$ & 0.575 \\
\hline \multicolumn{4}{|l|}{ Laboratory test } \\
\hline Leucocyte $\left(10^{9} / \mathrm{L}\right)$ & $11.8 \pm 3.8$ & $13.0 \pm 3.3$ & 0.086 \\
\hline Hemoglobin (g/L) & $134.0(124.0,143.0)$ & $137.5(124.8,150.3)$ & 0.652 \\
\hline Platelet $\left(10^{9} / \mathrm{L}\right)$ & $162.0(127.0,212.0)$ & $161.5(140.5,200.0)$ & 0.726 \\
\hline $\mathrm{ALT}(\mathrm{U} / \mathrm{L})$ & $27.0(20.0,39.5)$ & $30.5(19.0,41.4)$ & 0.934 \\
\hline Creatinine $(\mu \mathrm{mol} / \mathrm{L})$ & $82.0(66.5,108.2)$ & $89.5(70.2,132.0)$ & 0.256 \\
\hline Troponin I (ng/ml) & $0.02(0.01,0.07)$ & $0.02(0.01,0.08)$ & 0.489 \\
\hline $\mathrm{PaO}_{2}(\mathrm{mmHg})$ & $83.5(70,99)$ & $80(67.7,109.2)$ & 0.132 \\
\hline \multicolumn{4}{|l|}{ Surgical procedure } \\
\hline Total arch replacement & $89(94.7)$ & $38(95.0)$ & 1.000 \\
\hline Hemi arch replacement & $5(5.3)$ & $2(5.0)$ & 1.000 \\
\hline Concomitant CABG & $9(9.6)$ & $2(5.0)$ & 0.377 \\
\hline \multicolumn{4}{|l|}{ CPB } \\
\hline CPB time (min) & $167.5(149.0,183.0)$ & $162.5(147.0,191.5)$ & 0.808 \\
\hline ACC time (min) & $97.5(84.0,109.3)$ & $96.0(87.3,117.3)$ & 0.569 \\
\hline DHCA time (min) & $26.0(20.8,30.0)$ & $24.0(19.0,28.0)$ & 0.143 \\
\hline Minimum temperature in $\mathrm{CPB}\left({ }^{\circ} \mathrm{C}\right)$ & $22.1(22.1,24.3)$ & $22.1(21.5,23.5)$ & 0.129 \\
\hline $\mathrm{PaO}_{2} / \mathrm{FiO}_{2}$ ratio meet hypoxemia criteria & 109.0(85.2, 130.1) & $95.0(82.9,127.1)$ & 0.524 \\
\hline
\end{tabular}

AADA Acute type A aortic dissection, PSM Propensity score-matching, iNO Inhaled nitric oxide, BMI Body mass index, COPD Chronic obstructive pulmonary disease,

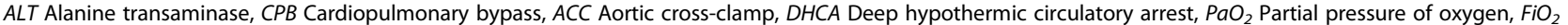
Fraction of inspired oxygen 
than in the control group (both $p<0.001$ ). There were no significant differences in mortality, complications, or lengths of hospital stay. Eight patients (6.0\%) died during the perioperative period, one in the iNO group due to sepsis, and 7 in the control group (2 from cardiac arrest and 5 from sepsis) (Table 3 ).

There were no significant differences in the $\mathrm{PaO}_{2} / \mathrm{FiO}_{2}$ ratios between the groups preoperatively, upon postoperative ICU admission and at the first time hypoxemia criteria were met $(p>0.05)$. After administration of iNO for $6 \mathrm{~h}$, the $\mathrm{PaO}_{2} / \mathrm{FiO}_{2}$ ratios in the iNO group were significantly higher than those in the control group (153.5 $(125.8-186.2)$ vs. $123.1 \quad(104.1-144.0) ; p<0.001)$. The $\mathrm{PaO}_{2} / \mathrm{FiO}_{2}$ ratios in two groups improved with time, but the differences remained significant at $24 \mathrm{~h}(161.7$ (125.4-197.3) vs. $125.3(100.3-148.8) ; p<0.001), 48 \mathrm{~h}$ (195.4 (147.3-253.1) vs. $156.8(128.3-202.7) ; p=0.004)$, and $72 \mathrm{~h}$ (258.8 (188.1-325.0) vs. 173.3 (134.4-220.2), $p<0.001$ ) (Fig. 2).

We also compared all outcomes between the two groups without PSM as a sensitivity analysis and found shorter durations of mechanical ventilation and ICU stay and better $\mathrm{PaO}_{2} / \mathrm{FiO}_{2}$ ratios, which corresponded with the results after PSM (see Additional file 1).

The $\mathrm{NO}_{2}$ concentration was continuously monitored during iNO administration and was maintained at $<0.6$ $\mathrm{ppm}$. The MetHb levels in the iNO group were less than
$1.5 \%$. Platelet counts and drainage were comparable between the groups $(p>0.05)$ (Tables 3$)$.

\section{Discussion}

To the best of our knowledge, this is the first retrospective case-control study to explore the efficacy and safety of iNO for the treatment of postoperative hypoxemia among patients with AADA. In the present study, lowdose iNO improved patient oxygenation gradually over a 3-day period, decreased the duration of mechanical ventilation, and reduced the ICU length of stay. There were trends toward less postoperative mortality and pneumonia, but no significant differences were observed.

iNO rapidly led to ventilation/perfusion matching, then ameliorated oxygenation in the injured lungs. Rossaint et al. [14] first reported that iNO improved oxygenation in patients with ARDS in 1993. Subsequent studies showed similar improvements in oxygenation in a dosedependent manner without better outcomes [10]. Multiple systematic reviews have shown that iNO does not reduce the mortality among patients with ARDS, nor does it shorten the duration of mechanical ventilation and it may even increase the incidence of renal impairment [9]. Nevertheless, one study showed that low iNO doses $(<5 \mathrm{ppm})$ improved lung function in ARDS survivors at 6 months [15]. Generally, iNO dilates blood vessels of ventilated alveoli and increases their blood flow,

Table 3 Primary and secondary outcomes after PSM

\begin{tabular}{|c|c|c|c|}
\hline Outcome & Control $(N=94)$ & iNO treatment $(N=40)$ & $p$-value \\
\hline \multicolumn{4}{|l|}{ Primary outcome } \\
\hline Mechanical ventilation time (hours) & $69.0(47.8,110.3)$ & $39.0(31.2,47.8)$ & $<0.001$ \\
\hline ICU stay (hours) & $179.5(114.0,258.0)$ & $122.0(80.8,155.0)$ & $<0.001$ \\
\hline \multicolumn{4}{|l|}{ Secondary outcome } \\
\hline Inpatient deaths N (\%) & $7(7.4)$ & $1(2.5)$ & 0.479 \\
\hline In-hospital stay (days) & $20.5(15.8,28.5)$ & $22.8(19.1,27.5)$ & 0.131 \\
\hline Postoperative drainage (24 h) & $470(325,750)$ & $495(260,667)$ & 0.216 \\
\hline Peak CRP (mg/L) & $7.1(2.4,85.7)$ & $8.0(2.6,37.9)$ & 0.676 \\
\hline \multicolumn{4}{|l|}{ Complication. } \\
\hline Cardiac arrest & $2(2.1)$ & $0(0.0)$ & 0.880 \\
\hline Re-intubation & $7(7.4)$ & $2(5.0)$ & 0.888 \\
\hline Pneumonia & $23(24.5)$ & $5(12.5)$ & 0.110 \\
\hline Hepatic insufficiency & $20(21.3)$ & $4(10.0)$ & 0.119 \\
\hline AKI & $55(58.5)$ & $19(47.5)$ & 0.241 \\
\hline CRRT & $7(7.4)$ & $2(5.0)$ & 0.605 \\
\hline Paraplegia & $1(1.1)$ & $0(0.0)$ & 0.513 \\
\hline Sepsis & $6(6.4)$ & $4(10.0)$ & 0.466 \\
\hline Re-exploration for bleeding & $2(2.1)$ & $2(5.0)$ & 0.734 \\
\hline thrombocytopenia & $28(29.8)$ & $13(32.5)$ & 0.755 \\
\hline
\end{tabular}

PSM Propensity score-matching, iNO Inhaled nitric oxide, ICU Intensive care unit, CRP C-reactive protein, AKI Acute kidney injury, CRRT Continuous renal replacement therapy 


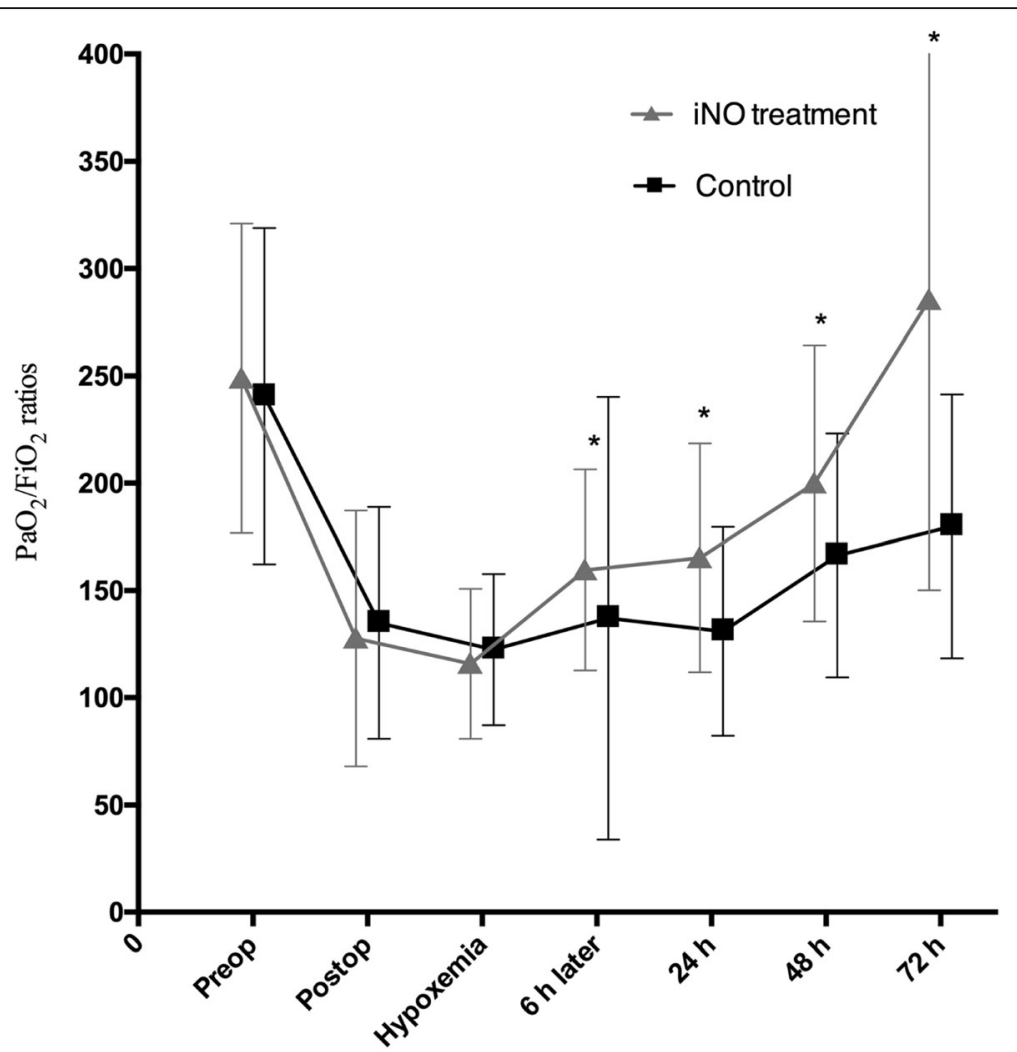

Fig. 2 Comparison of perioperative $\mathrm{PaO} 2 / \mathrm{FiO} 2$ ratios between the iNO and control groups. ${ }^{*} p<0.01$ compared with oxygenation index before iNO. iNO: inhaled nitric oxide

thereby counteracting the ventilation/perfusion mismatch [16]. Improvements in oxygenation occur rapidly, but the treatment does not practically resolve the disease. If the disease progresses, the alveoli will continue to collapse and the effects of iNO will disappear over several days. In our study, causes of lung injury, such as vessel rupture and $\mathrm{CPB}$, were eliminated by the time the surgery was completed. This may be why the effects of iNO on oxygenation were obvious and sustained. Our results are similar to those of Prendergast et al. in their treatment of hypoxemia with iNO after coronary artery bypass grafting [17].

Another possible mechanism behind the beneficial outcomes after iNO is related to its anti-inflammatory effects. NO is involved in various physiological and pathological processes. It can be either protective or destructive in different conditions and according to the dose and time course $[16,18]$. Studies in different animal models have demonstrated that iNO ameliorates lung injury by inhibiting inflammatory cytokines and oxidative damage [19-21]. A recent study on iNO-mediated prevention of bronchopulmonary dysplasia in Europe showed that iNO treatment may decrease several inflammatory and fibrotic factors in the lungs [22]. Preemptive iNO in human liver transplantation surgery led to clear anti-inflammatory effects in liver grafts which protected graft function, ameliorated pathological changes, and reduced postoperative morbidity [23]. In our study, we found no evidence of inflammation modulation since postoperative $\mathrm{C}$-reactive protein levels were similar in the two groups. However, we speculate that the effects of iNO were associated with regulation of inflammation for several reasons: (1) systemic inflammation causes perioperative hypoxemia in AADA [24]; (2) treatments using systemic antiinflammatory medicines such as glucocorticoid, sivelestat, and ulinastatin could play a role in attenuating hypoxemia $[25,26]$. In our study, there was a trend toward lower inpatient mortality in the iNO treatment group, but this was not significant. Patients with AADA often were in critical condition and could have had complications other than lung injury.

Some ARDS studies indicated that iNO can adversely affect renal function [9]; however, the mechanism is unclear. A recent study showed that the administration of $80 \mathrm{ppm} \mathrm{NO}$ gas into the extracorporeal circulation in conjunction with postoperative iNO treatment significantly reduced the occurrence of renal dysfunction after valve replacement surgery [27]. 
Recently, Hyun-Su et al. reported that iNO did not worsen renal function after lung transplantation; nearly half of the patients in that study were administered extracorporeal membrane oxygenation [28]. In this study, the incidence of AKI and use of continuous renal replacement therapy (CRRT) were similar between the two groups.

During iNO treatment, routine MetHb and exhaled $\mathrm{NO}_{2}$ monitoring are required. With low-dose iNO, the concentrations of those two substances are small and stable; their safety has been confirmed in other studies of iNO in infants [22]. Another possible side-effect of iNO is that it can inhibit platelet aggregation and adhesion to the vascular endothelium, thereby prolonging bleeding time. We compared the number of patients with thrombocytopenia, daily pleural effusions, and those who underwent reoperations and found no significant between-group differences. However, active bleeding remained a contraindication to iNO. The price of iNO is about 1200 RMB per day (Chinese currency), which is equivalent to almost 174. USD per day and the average duration of iNO therapy was 3 days. The total in-hospital expenses of the two groups were similar (data not shown).

\section{Study limitations}

Our study had several limitations. First, this was a retrospective study with a small sample size; therefore, potential biases could not be fully avoided. Because we did not calculate the required sample size before the study, the potential difference of outcomes may not be showed due to the underpower. A multicenter RCT with larger sample size would add more weight to these results. Second, we lacked long-term follow-up data on our patients. Thus, it is not clear how iNO affected the patients after discharge. Third, Selection of patients who had iNO remains elusive despite PSM and further prospective RCT is needed to identify patients who will benefit from iNO.

\section{Conclusion}

This study showed that low-dose iNO treatment possibly improved pulmonary oxygenation and shortened the durations of mechanical ventilation and ICU stays among patients with hypoxemia after AADA. There were no clinical side-effects and no effects on postoperative morbidity and mortality. Therefore, further perspective multicenter trials to clarify the effect and mechanisms of iNO are necessary.

\section{Supplementary information}

Supplementary information accompanies this paper at https://doi.org/10. 1186/s13019-020-1069-6.

Additional file 1. Primary and secondary outcomes before PSM.

\section{Abbreviations}

AADA: Acute type A aortic dissection; ABG: Arterial blood gases; ACC: Aortic cross-clamp; AKI: Acute kidney injury; ALT: Alanine transaminase; ARDS: Acute respiratory distress syndrome; BMI: Body mass index; CABG: Coronary artery bypass graft; COPD: Chronic obstructive pulmonary disease; CPB: Cardiopulmonary bypass; CRP: C-reactive protein; CRRT: Continuous renal replacement therapy; DHCA: Deep hypothermic circulatory arrest; eGFR: Estimated glomerular filtration rate; FiO2: Fraction of inspired oxygen; ICU: Intensive care unit; iNO: Inhaled nitric oxide; $\mathrm{PaO} 2$ : Partial pressure of oxygen; PEEP: Positive end-expiratory pressure; PSM: Propensity scorematching; SIMV: Synchronized intermittent mandatory ventilation

\section{Acknowledgements}

We want to thank the statistician of statistical guidance of this work: Weituo Zhang. PhD, Tienan Feng. PhD, worked in clinical research center of Shanghai Jiao Tong University School of Medicine.

\section{Authors' contributions}

We confirm that the manuscript has been read and approved by all named authors and that there are no other persons who satisfied the criteria for authorship but are not listed. We further confirm that the order of authors listed in the manuscript has been approved by all of Us. MY, YL participated in conception and design of the study. XM, DY, SS, JL, ZY, TG obtained, organized and cleaned the dataset. MY, YL, LH, FL, ZX drafted the article and all authors provided critical revisions of the article. $\mathrm{HZ}, \mathrm{YL}$ performed data analyses.

\section{Funding}

This work was supported by the National Natural Science Foundation of China (No. 81873524,81770411,81300094), China Postdoctoral Science Foundation funded project (NO. 2018 M633709), Shanghai Health Commission Science Surface Project (201640294), Clinical Research Plan of Shanghai Hospital Development Center (16CR3086B).

\section{Availability of data and materials}

All data have been retrieved from the institutional data base and are available from the corresponding author on reasonable request.

\section{Ethics approval and consent to participate}

The Institutional Review Board reviewed and approved the study. Consent to participate for this study was waived because no individual patients were identified.

Consent for publication

Not applicable.

\section{Competing interests}

The authors declare that they have no competing interests.

\section{Author details}

'Department of Cardiovascular Surgery, Shanghai General Hospital, Shanghai Jiao Tong University School of Medicine, No. 100 Haining Road, Shanghai 200080, China. ${ }^{2}$ Department of Cardiovascular Surgery, Shanghai General Hospital, Nanjing Medical University, Shanghai 200080, China. ${ }^{3}$ Department of Rheumatology and Immunology, Changzheng Hospital, Second Military Medical University, 415 Fengyang Road, Shanghai 200000, China.

${ }^{4}$ Department of Central laboratory, Nanjing First People's Hospital, Nanjing Medical University, NO.68 Changle Road, Nanjing 210006, China.

${ }^{5}$ Department of Cardiovascular Surgery, Changhai Hospital, Second Military Medical University, Shanghai 200433, China. ${ }^{6}$ Department of Critical Care

Medicine, Naval medical Center of PLA, Shanghai 200433, China.

Received: 31 March 2019 Accepted: 7 January 2020

Published online: 22 January 2020

\section{References}

1. Pape LA, Awais M, Woznicki EM, et al. Presentation, diagnosis, and outcomes of acute aortic dissection: 17-year trends from the international registry of acute aortic dissection. J Am Coll Cardiol. 2015;66:350-8.

2. Nienaber CA, Clough RE. Management of acute aortic dissection. Lancet. 2015;385:800-11. 
3. Liu N, Zhang W, Ma W, et al. Risk factors for hypoxemia following surgical repair of acute type a aortic dissection. Interact Cardiovasc Thorac Surg. 2017;24:251-6.

4. Kurabayashi $\mathrm{M}$, Okishige $\mathrm{K}$, Azegami $\mathrm{K}$, et al. Reduction of the $\mathrm{PaO} / \mathrm{FiO} 2$ ratio in acute aortic dissection - relationship between the extent of dissection and inflammation. Circ J. 2010;74:2066-73.

5. Luo F, Zhou XL, Li JJ, et al. Inflammatory response is associated with aortic dissection. Ageing Res Rev. 2009:8:31-5.

6. Apostolakis E, Filos KS, Koletsis E, et al. Lung dysfunction following cardiopulmonary bypass. J Card Surg. 2010;25:47-55.

7. Stephens RS, Shah AS, Whitman GJ. Lung injury and acute respiratory distress syndrome after cardiac surgery. Ann Thorac Surg. 2013;95:1122-9.

8. Kimura N, Tanaka M, Kawahito K, et al. Risk factors for prolonged mechanical ventilation following surgery for acute type a aortic dissection. Circ J. 2008:72:1751-7.

9. Gebistorf F, Karam O, Wetterslev J, et al. Inhaled nitric oxide for acute respiratory distress syndrome (ARDS) in children and adults. Cochrane Database Syst Rev. 2016;27:CD002787

10. Gerlach H, Keh D, Semmerow A, et al. Dose-response characteristics during long-term inhalation of nitric oxide in patients with severe acute respiratory distress syndrome: a prospective, randomized, controlled study. Am J Respir Crit Care Med. 2003;167:1008-15.

11. Min YU, Mao JQ, Fan $Y L$, et al. Effects of inhaled nitric oxide in refractory hypoxemic patients after open heart surgery. J Shanghai Jiaotong Univ. 2014;34:343-51.

12. Girdauskas $E$, Kuntze T, Borger MA, et al. Acute respiratory dysfunction after surgery for acute type a aortic dissection. Eur J Cardiothorac Surg. 2010;37:691-6.

13. Wang YF, Liu CQ, Gao XR, et al. Effects of inhaled nitric oxide in neonatal hypoxemic respiratory failure from a multicenter controlled trial. Chin Med J (Engl). 2011;124:1156-63.

14. Rossaint R, Falke KJ, Lopez F, et al. Inhaled nitric oxide for the adult respiratory distress syndrome. New Engl J Med. 1993;328:399-405.

15. Dellinger RP, Trzeciak SW, Criner GJ, et al. Association between inhaled nitric oxide treatment and long-term pulmonary function in survivors of acute respiratory distress syndrome. Crit Care. 2012;16:R36.

16. Griffiths MJ, Evans TW. Inhaled nitric oxide therapy in adults. New Engl J Med. 2005;353:2683-95.

17. Prendergast B, Scott DH, Mankad PS. Beneficial effects of inhaled nitric oxide in hypoxaemic patients after coronary artery bypass surgery. Eur J Cardiothorac Surg. 1998;14:488-93.

18. Bhatraju P, Crawford J, Hall M, et al. Inhaled nitric oxide: current clinical concepts. Nitric Oxide. 2015;50:114-28.

19. Qian L, Liu H, Yu W, et al. Effects of positive end-expiratory pressure, inhaled nitric oxide and surfactant on expression of proinflammatory cytokines and growth factors in preterm piglet lungs. Pediatr Res. 2008;64:17-23.

20. El Kebir D, Hubert B, Taha R, et al. Effects of inhaled nitric oxide on inflammation and apoptosis after cardiopulmonary bypass. Chest. 2005;128: 2910-7.

21. Waldow T, Alexiou K, Witt W, et al. Attenuation of reperfusion-induced systemic inflammation by preconditioning with nitric oxide in an in situ porcine model of normothermic lung ischemia. Chest. 2004;125:2253-9.

22. Laube $M$, Amann $E$, Uhlig $U$, et al. Inflammatory mediators in tracheal aspirates of preterm infants participating in a randomized trial of inhaled nitric oxide. PLoS One. 2017;12:e0169352.

23. Lang JD Jr, Smith AB, Brandon A, et al. A randomized clinical trial testing the anti-inflammatory effects of preemptive inhaled nitric oxide in human liver transplantation. PLoS One. 2014;9:e86053.

24. Wen D, Zhou XL, Li JJ, et al. Plasma concentrations of interleukin-6, Creactive protein, tumor necrosis factor-alpha and matrix metalloproteinase-9 in aortic dissection. Clin Chim Acta. 2012;413:198-202.

25. Morimoto N, Morimoto K, Morimoto Y, et al. Sivelestat attenuates postoperative pulmonary dysfunction after total arch replacement under deep hypothermia. Eur J Cardiothorac Surg. 2008;34:798-804.

26. Xu CE, Zou CW, Zhang MY, et al. Effects of high-dose ulinastatin on inflammatory response and pulmonary function in patients with type-a aortic dissection after cardiopulmonary bypass under deep hypothermic circulatory arrest. J Cardiothorac Vasc Anesth. 2013;27:479-84.

27. Lei $C$, Berra L, Rezoagli E, et al. Nitric oxide decreases acute kidney injury and stage 3 chronic kidney disease after cardiac surgery. Am J Respir Crit Care Med. 2018;198:1279-87.
28. Ri HS, Son HJ, Oh HB, et al. Inhaled nitric oxide therapy was not associated with postoperative acute kidney injury in patients undergoing lung transplantation: A retrospective pilot study. Medicine (Baltimore). 2018:97:e10915.

\section{Publisher's Note}

Springer Nature remains neutral with regard to jurisdictional claims in published maps and institutional affiliations.
Ready to submit your research? Choose BMC and benefit from:

- fast, convenient online submission

- thorough peer review by experienced researchers in your field

- rapid publication on acceptance

- support for research data, including large and complex data types

- gold Open Access which fosters wider collaboration and increased citations

- maximum visibility for your research: over $100 \mathrm{M}$ website views per year

At BMC, research is always in progress.

Learn more biomedcentral.com/submissions 